Nigerian Journal Of Physiological Sciences 21 (1-2): 15-19 @ Physiological Society Of Nigeria, 2006

Available online/abstracted at http://www.biolineinternational.org.br/njps; www.ajol.info/journals.njps; www.cas.org

\title{
EFFECT OF VITAMIN C ON SERUM LIPIDS AND ELECTROLYTE PROFILE OF ALBINO WISTAR RATS.
}

\author{
M. U ETENG*, H. A. IBEKWE ${ }^{2}$, T. E. AMATEY, B. J. BASSEY, \\ F. U. UBOH, and D. U. OWU ${ }^{1}$,

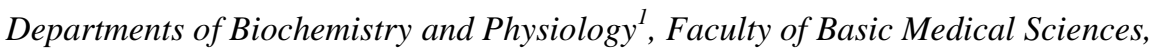 \\ University of Calabar, Calabar \\ Department of Pharmacology ${ }^{2}$ Faculty of Laboratory and Allied Health Sciences, \\ University of Calabar, Calabar
}

\begin{abstract}
Summary: The effect of oral administration of vitamin $\mathrm{C}$ on serum lipids and electrolyte profile were investigated in albino rats of the Wistar strain. Eighteen (18) albino rats of opposite sexes weighing between 150-300g were used for the study and randomly assigned on the basis of body weight and litter origin to three study groups of six animals each. The control group received via oral route a placebo ( $4 \mathrm{ml}$ of distilled water), while test groups 1 and II received $100 \mathrm{mg} / \mathrm{kg}$ body weight and $200 \mathrm{mg} / \mathrm{kg}$ body weight of vitamin $\mathrm{C}$ in $2.5 \mathrm{ml}$ and $5.0 \mathrm{ml}$ of the vehicle via gastric intubation respectively. The administration of vitamin $\mathrm{C}$ for 30 days produced a significant $(\mathrm{P}<0.05)$ decrease in total cholesterol (TC), very low-density lipoprotein (VLDL) and low density lipoprotein (LDL) in the test groups versus control but there was no change in triglycerides (TG) and High density lipoprotein (HDL) levels. Computed HDL: LDL ratio also increased in the treatments relative to the control. Except for computed HDL: LDL ratio all the other changes were dose dependent and there was a slight non-significant increase in all electrolytes $\left(\mathrm{Na}^{+}, \mathrm{K}^{+}\right.$and $\left.\mathrm{HCO}_{3}^{-}\right)$ions. The study confirms the hypocholesterolaemic effect of vitamin $\mathrm{C}$ and that Vitamin $\mathrm{C}$ has no adverse effect on serum electrolytes. It is suggested that its administration in moderate to high doses may protect against atherosclerosis and hypertension.
\end{abstract}

Key Words: Vitamin C, serum lipid electrolyte, atherosclerosis and hypertension.

\section{Introduction}

Vitamin C or ascorbic acid, also known as antiscorbutic vitamin is an "enediolactone" of an acid similar to L-glucose. Plants and almost all animals except primates and guinea pigs synthesize this vitamin. It is watersoluble and widely distributed in plants and animal tissues. Prolonged deficiency in man results to a condition known as scurvy.

Essentially, there are no storage forms of this vitamin in animal tissues but there is high concentrations in "metabolically highly active" organs such as adrenal cortex, liver, corpus luteum (Chatterjea and Shinde, 2002). Dietary sources consist chiefly of vegetables and fruits (Annette and John, 1985). Fruits are very important sources of vitamin C. These include citrus fruits, orange, lemon, lime, pineapple, paw-paw and strawberry, vegetable sources include cabbage, cauliflower, green peas, potatoes and tomatoes, with amla as the richest source. Considerable amount of vitamin C activity is lost during cooking, processing and storage because of its water solubility and its irreversible oxidative degradation to inactive compounds. The biological significance of this vitamin is evidenced by associated deficiency disorders especially scurvy characterized by haemorrhages, and impaired collagen formation (White et al, 1978).

This vitamin is concerned with synthesis of mucopolysaccharides of basement membranes of epithelial tissues, collagen and also in wound healing as well as antibody synthesis and healthy dentition. The activity of this vitamin is also significant in vital metabolic activities including tryptophan metabolism, formation of active tetrahydrofolate, formation of ferritin as cellular antioxidant, iron absorption, electron transport system, catecholamine synthesis, omega-oxidation of fatty acids and coenzyme for cathepsin and liver esterases (Chartterjea and Shinde, 2002). 
An association between vitamin $\mathrm{C}$ and atherosclerosis has been suggested in studies that evaluated the relationship between vitamin C and cholesterol levels (Spittle, 1972; Dubic and Hunter, 1987). Relationship of ascorbic acid with hypocholesterolaemia in man and guinea pigs has been reported (Kurowska et al, 2000). Ascorbic acid levels were also found to be lower in patients with diagnosis of cardiac infarction and diabetes mellitus (Chatterjea and Shinde, 2002).

There was however, a contrasting report indicating negative ascorbic acid and serum cholesterol levels amongst Indians, especially in patients with infarctions. More so, Spittle (1972) reported that no consistent pattern of serum cholesterol change was seen in older people upon consumption of a normal diet supplemented with $1 \mathrm{gm}$ of vitamin $\mathrm{C}$ per day.

This study is aimed at establishing a clear relationship between moderate to high levels of vitamin $\mathrm{C}$ in take and serum lipids as well as electrolytes. This will contribute to its preventive and therapeutic benefits or otherwise in atherosclerosis, coronary heart disease (CHD) and hypertension.

\section{Materials and Methods}

Experimental Animals:

A total of 18 adult albino rats of both sexes weighing between $150-300 \mathrm{~g}$ obtained from the disease free stock of the animal house, Biochemistry Department, College of Medical Sciences University of Calabar, Calabar Nigeria, were used for the study. The animals were randomly assigned on the basis of average body weight and litter origin into three study groups of 6 animals each. Each rat in a study group was individually housed in a stainless steel cage with plastic bottom grid and a wire screen top.

The animal room was adequately ventilated, and kept at room temperature and relative humidity of $29 \pm 2^{\circ} \mathrm{C}$ and $40-70 \%$ respectively with a 12-hour natural light-dark cycle. They were fed ad libitum with water and rat chow (Zion feed, Calabar Nigeria). Good hygiene was maintained by constant cleaning and removal of faeces and spilled feed from cages daily. Test groups I and II received $100 \mathrm{mg} / \mathrm{kg}$ body weight and 200/mg/kg body weight oral doses of vitamin $\mathrm{C}$ respectively administered to the rats using orogastric tubes and syringes. This lasted for a period of 30 days and the experiments were conducted between the hours of 09.00 am and 10.00am daily. Rats in the control group III were administered by oral gavage, with $4 \mathrm{ml}$ of distilled water (placebo).
Preparation of Blood Serum and Assays:

Twenty four hours after the administration of the last dose of vitamin $\mathrm{C}$ and placebo on test groups and control respectively, the animals were sacrificed by inhalation of an over dose of chloroform. Blood samples were collected by cardiac puncture into sterilized sample test tubes, serum was prepared by centrifugation and used for serum lipid and electrolyte analysis.

\section{Assay of Lipid Profile:}

Component lipids were estimated using enzymatic colorimetric diagnostic kits obtained from Randox Laboratories, Antrium, United Kingdom BT 294 QY, in which the GPO-PAP method of Trinder (1969) was used for the determination of serum triglycerides. The same GPO - PAP method was also used for estimation of total cholesterol.

The phosphotungstate precipitation method of Richmond (1973) as applied in Randox kits were used in conjunction with Teco diagnostic kits (Placentia CA92670) for the determination of HDL-cholesterol. The very low-density lipoprotein (VLDL) cholesterol content of serum was determined by calculation from determined triglyceride concentration according to method of Burnstein and Samaille (1960). The serum triglyceride concentration was divided by a factor 5. This factor was based on the understanding that in a fasting human subject with triglycerides concentration of $400 \mathrm{mg} / \mathrm{dl}$, the VLDL to total plasma cholesterol ratio is relatively fixed at 1:5. The low-density lipoprotein (LDL) cholesterol was estimated as the difference between the total cholesterol and the sum of HDL-cholesterol and VLDL cholesterol (Friedewald et al, 1972).

\section{Assay of Serum Electrolytes:}

The flame photometry method of Vogel (1960) was used for the determination of sodium ion $\left(\mathrm{Na}^{+}\right)$and potassium ion $\left(\mathrm{K}^{+}\right)$ concentration in serum while chloride ion $\left(\mathrm{Cl}^{-}\right)$ and bicarbonate ion $\left(\mathrm{HCO}_{3}{ }^{-}\right)$concentration in serum were determined using the titration methods of AOAC (1984).

\section{Chemical: Vitamin C}

Synthetic vitamin C was obtained from the Sigma Chemicals, Poole England and used for the study. A stock solution of vitamin C was prepared by dissolving $20 \mathrm{~g}$ of vitamin $\mathrm{C}$ powder in $500 \mathrm{ml}$ of distilled water out of which a low dose $100 \mathrm{mg} / \mathrm{kg}$ body weight and a high dose, $200 \mathrm{mg} / \mathrm{kg}$ body weight was administered to animals in $2.5 \mathrm{ml}$ and $5 \mathrm{ml}$ of vehicle respectively. 
Statistics

Data collected were expressed as mean $\underline{ \pm}$ standard deviation (SD) and the Student ' $\mathrm{t}$ ' test were used for analysis. Values of $\mathrm{P}<0.05$ were regarded as significant.

\section{Result}

The effect of oral administration of vitamin $\mathrm{C}$ on lipid parameters $(\mathrm{mmol} / \mathrm{L})$ of Wistar rats is presented in Table 1 . The result indicate that there was no significant change in the values of HDL and TG of the test groups relative to the control but there was significant $(\mathrm{P}<0.05)$ decrease in total serum cholesterol, VLDL and LDL in the treatment group compared with the control.
The values for treatment groups I, II and control group for serum cholesterol were 0.099 $\pm 0.20,0.087 \pm 0.030$ and $0.104 \pm 0.010$ respectively. Those for VLDL were $0.042 \pm$ $0.000, \quad 0.041 \pm 0.000$ and $0.052 \pm 0000$ respectively while those for LDL were $0.014 \pm$ $0.10,0.021 \pm 0.030$ and $0.023 \pm 0.000$ respectively. The HDL to LDL ratio increased from $0.239 \pm 0.010$ in control to $5.114 \pm 1.000$ in group I but the values of $3.191 \pm 0.000$ obtained in test group II indicates that the increase was not dose dependent.

Table II summarizes the effect of oral vitamin $\mathrm{C}$ administration on electrolyte profiles $(\mathrm{mmol} / \mathrm{L})$. There was a slight nonsignificant increase in all the electrolyte parameters relative to the control group.

Table I: Effect of Oral Administration of Vitamin C on Lipid Parameters of Albino Wistar Rats $(\mathrm{mmol} / \mathrm{L})$

\begin{tabular}{lllllll}
\hline \multicolumn{1}{c}{ Study Group } & \multicolumn{1}{c}{ TG } & $\begin{array}{c}\text { Cholestero } \\
\mathbf{l}\end{array}$ & VLDL & LDL & HDL & $\frac{\text { HDL }}{\text { LDL }}$ \\
\hline I. 100mg/kg & 0.211 & 0.099 & 0.042 & 0.014 & 0.071 & 5.114 \\
body weight & \pm 0.010 & $\pm 0.020^{*}$ & $\pm 0.000^{*}$ & $\pm 0.010^{*}$ & \pm 0.010 & $\pm 1.000^{*}$ \\
II. 200mg/kg & 0.206 & 0.087 & 0.041 & 0.021 & 0.067 & 3.191 \\
body weight & \pm 0.020 & $\pm 0.030^{*}$ & $\pm 0.000^{*}$ & $\pm 0.030^{*}$ & \pm 0.000 & $\pm 0.000^{*}$ \\
III. Distilled & 0.210 & 0.104 & 0.052 & 0.023 & 0.074 & 0.239 \\
Water & \pm 0.010 & \pm 0.010 & \pm 0.000 & \pm 0.000 & \pm 0.010 & \pm 0.010 \\
\hline
\end{tabular}

Values are mean \pm Standard deviation, $*$ Statistically significant $(P<0.05)$ compared to the control.

Table II: Effect of Oral Administration of Vitamin C on Electrolyte Parameters (mmol/l) of serum Albino Wistar Rats.

\begin{tabular}{lcccc}
\hline \multicolumn{1}{c}{ Study Group } & $\mathrm{Na}^{+}$ & $\mathrm{K}^{+}$ & $\mathrm{CL}^{-}$ & $\mathrm{HC}_{3}^{-}$ \\
\hline I. 100mg/kg body weight & $104.00 \pm 11.31$ & $6.72 \pm 1.44$ & $96.54 \pm 13.66$ & $19.60 \pm 4.03$ \\
II. $200 \mathrm{mg} / \mathrm{kg}$ body weight & $102.40 \pm 21.41$ & $6.80 \pm 0.98$ & $96.72 \pm 5.45$ & $19.70 \pm 3.03$ \\
III. Control Distilled Water & $102.00 \pm 17.44$ & $6.40 \pm 0.80$ & $95.45 \pm 7.88$ & $19.13 \pm 1.43$
\end{tabular}

Values are mean \pm standard deviations

\section{Discussion}

The effect of vitamin $\mathrm{C}$ oral administration on serum lipid profile and electrolyte was investigated in albino Wistar rats. The result showed that there was a significant $(\mathrm{P}<0.05)$ decrease in the lipid profile of total cholesterol (TC), very lowdensity lipoprotein (VLDL) and a non significant increase in high density lipoprotein (HDL) (Table 1). The present result agree with previous reports as documented by
Chatterjea and Shinde (2002) which observed a reduction in serum cholesterol in experimental animals administered with vitamin $\mathrm{C}$, and of recent, the ability of the vitamin to inhibit the oxidation of HDL even in humans (Hillstrom, 2003).

A plausible explanation for the observed effect on serum lipids may be due to the activation of the enzyme $7 \alpha$-hydroxylase by vitamin $\mathrm{C}$ which enhances the conversion of plasma cholesterol into bile acid hence 
resulting in a decrease in serum levels of cholesterol. In fact Mayes (1996) observed that deficiency of vitamin $\mathrm{C}$ inhibits $7 \alpha$ hydroxylase leading to the block in bile acid synthesis and accumulation of cholesterol in serum with subsequent athereosclerosis in scorbutic Guinea pigs. Steroid hormones synthesis requires cholesterol as the precursors and vitamin $\mathrm{C}$ plays a role in hydroxylating the steroid hormone in the adrenal glands. It also directly meditates through a rate limiting hydroxylation of side chains, the conversion of cholesterol into steroid hormones as documented by White et al, (1978). The reduction in LDL-cholesterol points to the fact that adequate vitamin $\mathrm{C}$ intake can reduce the incidence of athereoslerosis. Both Anderson et $a l$, (1999) and Bsoul and Terezhalmy (2004) noted that animal fed on vitamin $\mathrm{C}$ had reduced risk of coronary Heart disease.

The observed decrease in total cholesterol, VLDL and most significantly the ability to lower the levels of the atherogenic predisposing factor (serum - LDL cholesterol) yet desirably increasing the level of HDL implies that dietary vitamin $\mathrm{C}$ on account of its effect on lipid profile may have a protective effect against arterioscerosis.

Sodium $\left(\mathrm{Na}^{+}\right)$ion and chloride $\left(\mathrm{Cl}^{-}\right)$ion excretion from the body is a function of arterial blood pressure (Guyton and Hall, 2006). Sodium $\left(\mathrm{Na}^{+}\right)$ion depletion stimulates rennin release and subsequence production of Angiotensin II, a potent vasoconstrictor (Guyton and Hall, 2005). Increased plasma sodium $\left(\mathrm{Na}^{+}\right)$ion levels inhibit rennin release from the juxtaglomerular cells and consequent withdrawal of angiotensin II (Jackson, 1984). When modulation of the rennin-angiotensin system is pharmacologically prevented, changes in salt intake markedly affect longterm levels of arterial blood pressure (Hall et al 1999). There is therefore a need to strike a balance in the levels of plasma $\left(\mathrm{Na}^{+}\right)$and $\left(\mathrm{Cl}^{-}\right)$ to avoid either of the extreme of hypotension or hypertension. The electrolyte profile result also obtained from this study showed a slight non significant increase in serum $\left(\mathrm{Na}^{+}\right)$level of $(102.00 \pm 17.44)$ for the control to $104.00 \pm$ $11.31 \mathrm{mmol} / \mathrm{L})$ for group I $(100 \mathrm{mg} / \mathrm{kg}$ body weight) representing $1.96 \%$ increase following administration of vitamin $\mathrm{C}$ to Wistar rats. On increasing the dosage of administration of vitamin $\mathrm{C}$ to $200 \mathrm{mg} / \mathrm{kg}$ body weight (group II) the serum $\left(\mathrm{Na}^{+}\right)$levels decreased from 104.00 \pm 11.31 to $102.40 \pm 21.41 \mathrm{mmol} / \mathrm{L}$ representing $1.55 \%$. These percentage increases were less than the critical value of (2.8 to $9.8 \%$ ) require to precipitate severe hypertension as documented by Deane et al (1952).

A small increase in plasma $\mathrm{K}^{+}$as small as $0.1 \mathrm{meq} / \mathrm{L}$ stimulates production of aldosterone whereas a similar decrease reduces aldosterone production and secretion. Increase in serum $\mathrm{K}^{+}$leads to hyperaldosteronism, however the increases in $\mathrm{K}^{+}$and $\mathrm{HCO}_{3}^{-}$ions levels in this study were not significant. Vitamin $\mathrm{C}$ administration does not adversely impact on plasma electrolytes and therefore does not predispose to hypertension.

On account of the ability of vitamin $\mathrm{C}$ to lower the atherogenic predisposing factor (serum LDL cholesterol) as well as elevating HDL cholesterol coupled with its impact on electrolyte profile, we conclude that moderate to high intake of vitamin $\mathrm{C}$ produces a hypocholesterolaemic effect and does not adversely affect serum electrolyte profile. It may therefore protects against arteriosclerosis and attendant coronary heart disease (CHD) and does not also predispose to hypertension.

\section{References}

Anderson, J. W., Gowri, M. S., Turner, J. (1999) Antioxidant supplementation effects low density lipoprotein oxidation for individuals with type 2 diabetes mellitus. J. Am. Coll. Nutr. 18: 457 461.

Annette, A. P. and John, M. S. (1985). Food Science, Nutrition and Health $6^{\text {th }}$ ed. Stephenson and Hodder, London. P. 156157.

A. O. A. C. (1984). Official Method of Analysis of the Association of Official Analytical Chemist. Washington.

Bsoul, S. A. and Terezhalmy, G. T. (2004) Vitamin $\mathrm{C}$ in health and disease $J$. Contemp. Dent. Pract. 15: 1 - 13.

Burnstein. M. and Samaille, J. (1960). A Rapid Determination of Cholesterol Bound to 7 and B Hyperborean Chin. Chem. Acta. 5: 604-635.

Chatterjea, M. N. and Shinde, R. (2002). Textbook of Medical Biochemistry $5^{\text {th }}$ edition AYPE pp. 154 - 157.

Deane, E. and Smith, H. W. (1952). The distribution of Sodium and Potassium in man . J. Clin. Invest. 31:197.

Dubic, M. S. and Hunter, G. C. (1987). Aortic ascorbic acid, trace elements and superoxide dismutase activity in Human aneyrismal and occlusive disease. Proc. Soc. Exp. Biol. Med. 184:18-143.

Friedewald, W. T., Levy, R. T. and Fredickson, D. S. (1972) Estimation of the concentration of LDL-cholesterol 
without use of plasma ultracentrifuge Clin. Chem. 18: 499 - 520.

Guyton, A. C. and Hall, J. E. (2006) Textbook of Medical Physiology, $11^{\text {th }}$ ed. Philadelphia, Elsevier and Saunders, pp. $358-381$.

Hall, J. E., Brands, M. W., Henegar, J. R. (1999). Angiotensin II and long term arterial pressure regulation: The overriding dominance of the kidney. $J$. Am. Soc. Nephrol 10 (suppl. 12): S258.

Hillstrom, R. J., Yacapin-Ammons, A. K., Lynch, S. M. (2003). Vitamin C inhibits lipid peroxidation in human HDL. $J$. Nutr.; 133 (10): 3047 - 3051.

Jackson, B. A. and Kotchen, T. A. (1984). Salt sensitive Hypertension Contribution of Chloride. Science 223; 1430-1432.

Kuvowska, E. M., Spence, J. D., Jordan, J., Wetmore, S., Freeman, D. J., Piche, L. A. and Servattore, P. (2000) HDL cholesterol raising effect of orange juice in subjects with hypercholesterolamia Am. J. Clin. Nutr. 72: 1095 - 1100.
Mayes, P. A. (1996). Cholesterol Synthesis, Transport and Excretion in Murrary, R. K. et. al; Harper's Biochemistry, $24^{\text {th }} 19$ Prince- Hall internal Inc. California. 1 A. p. 271-280.

Richmond, W. (1973). Cholesterol enzymatic colorimetric test chop- PAP method of estimation of total cholesterol in serum. Clin. Chem. 191: 1350-1356.

Spittle, C. R. (1972). Arteriosclerosis and Vitamin C. Lancet 1: 798.

Trinder, P. (1969) Triglycerides estimation by GPO-PAP method. Ann. Clin. Chem. 6: $24-27$.

Vogel, A. I. (1960). A Textbook of Quantitative Inorganic Analysis. Longman Group Ltd. London. $3^{\text {rd }}$ ed. p. 882-885.

White, A., Handler, P., Smith, E. L., Hill, R. L. and Cehman, R. (1978). Principles of Biochemistry McGraw Hill Kogakusha Ltd. Tokyo pp. 1223, 1360.

Received: 22/2/06

Accepted: 13/10/06 